\title{
BLINDANDO RELACIONAMENTOS: NARRATIVAS TERAPÊUTICAS E RACIONALIZAÇÃO DOS AFETOS NA ESCOLA DO AMOR
}

\author{
Bulletproofing Relationships:
}

Therapeutic narratives and the rationalization of affection in The Love School

\author{
Las Relaciones de Blindaje: \\ Las narrativas terapéuticas y racionalización de los afectos en La Escuela De \\ Amor
}

Karla Macena Patriota

Professora Associada da Universidade Federal de Pernambuco - UFPE

k.patriota@gmail.com

Vander Casaqui

Professor do Programa de Pós-graduação em Comunicação da ESPM - SP vander.casaqui@gmail.com

Emanuelle Rodrigues

Professora da Universidade Federal de Alagoas - UFAL

egbrodrigues@gmail.com

\section{Resumo}

Neste artigo, partindo da premissa de que o campo religioso tem atuado na construção de discursos prescritivos sobre a gestão de si, fazendo aflorar afetos racionalizados, apropriados pelo sistema capitalista e enquadrados em narrativas que apresentam fórmulas para se alcançar a felicidade, propomos uma reflexão sobre a relação entre fé racional/inteligente, relacionamentos afetivos e 'casamento empresa' a partir da análise das narrativas terapêuticas do casal Renato e Cristiane Cardoso e seus desdobramentos na marca The Love School, disponibilizados em diversos espaços, como televisão aberta, internet, livros e no principal templo da Igreja Universal do Reino de Deus - IURD, em São Paulo.

Palavras-chave: Narrativas terapêuticas. The Love School. Racionalização dos afetos.

\begin{abstract}
In this article, given the premise that religion has constructed prescriptive discourses on how to manage oneself, generating rationalized relations that are appropriated by the capitalist system and thus framed as formulas to reach happiness. We advance a reflection on the relation between "rational" or "intelligent" faith, emotional relationships and the "business marriage." Our study will analyze the therapeutic narratives exposed by Renato and Cristiane
\end{abstract}


Cardoso, as well as its ramifications within the Love School brand - in books, broadcast TV, Internet, and especially in the Universal Church of the Kingom God's temple in São Paulo.

Key words: Therapeutic narratives. The Love School. Rationalization of affection.

\section{Resumen}

En este artículo, en la premisa de que el campo religioso ha estado activa en la construcción de discursos prescriptivos sobre la gestión en sí, por lo que surgen afectos simplificados, apropiada por el sistema capitalista y enmarcado en las narrativas que presentan las fórmulas para alcanzar la felicidad, proponemos una reflexión sobre la relación entre fe inteligente/racional, relaciones afectivas y 'el matrimonio como empresa ' a partir del análisis de las narrativas terapéutica del pareja Renato y Cristiane Cardoso y sus consecuencias en la marca de la Escuela de Amor, disponible en varios espacios, como la televisión, internet, libros y el principal templo de la Iglesia Universal del Reino de Dios - IURD en Sao Paulo .

Palabras clave: Narrativas terapéuticas. La Escuela Del Amor. Racionalización de los afectos.

\section{INTRODUÇÃO}

As duas principais características que definem o panorama religioso no contexto atual são, paralelamente, a individualização das formas de crer e o aumento do número de instituições religiosas em uma situação típica de mercado. Ambas fazem parte de um processo mais amplo a que Berger (1985) chama de secularização. No nível sociocultural trata-se da subtração de setores da sociedade e da cultura "à dominação das instituições e símbolos religiosos. [...] E, sobretudo, na ascensão da ciência, como uma perspectiva autônoma e inteiramente secular do mundo" (BERGER, 1985, p.119). Por outro lado, no nível individual, tem-se o crescente número de pessoas "que encaram o mundo e suas próprias vidas sem o recurso às interpretações religiosas" (Ibid, p.120).

O indivíduo, portanto, encontra-se no centro da preocupação contemporânea, especialmente quando consideramos o consumo como uma das práticas mais estruturadoras das relações sociais e da produção de identidades, respaldando o comportamento dos agentes do campo econômico. Emerge, nesse cenário, uma série de discursos sobre a gestão de si e dos sentimentos, que convergem para a estruturação de uma cultura dos afetos - pautada em valores econômicos e de troca - em evidência no mercado de autoajuda. Este, por sua vez, engloba um complexo conjunto de narrativas, que trafegam e se apropriam das características 
dos mais diversos campos, inclusive do religioso, para a construção de relatos e aconselhamentos sensíveis a um público amplo. É o caso do nosso objeto de análise, uma marca de produtos voltados para resolução de conflitos amorosos e tratamento de questões no universo das relações pessoais, principalmente, as de ordem afetiva.

Com a proposta de ser uma "Escola do Amor" (assinada como The Love School, inclusive), a marca possui diversos produtos e serviços ${ }^{1}$ que apresentam aos consumidores modos práticos e racionais para lidar com seus sentimentos e agir no relacionamento a dois, principalmente como uma equipe em prol do mesmo objetivo - ideia que dialoga com a noção de "fé inteligente" ou "racional", apresentada pelo bispo Edir Macedo (MACEDO, 2010), líder da Igreja Universal do Reino de Deus (IURD), instituição a qual a The Love School está vinculada.

Os representantes, Renato e Cristiane Cardoso, ensinam, a partir de seus exemplos de vida e da experiência com o tratamento de casais em todo o mundo, uma fórmula simples e inteligente para resolver conflitos e evitar divórcios, que é "tratar o casamento como uma empresa" (CARDOSO; CARDOSO, 2012). Ele é um bispo da instituição, responsável pelo culto da Terapia do Amor, que ocorre todas as quintas-feiras no Templo de Salomão, em São Paulo. Ela é filha de Edir Macedo, o fundador da igreja. Ambos possuem projetos pedagógicos e sociais voltados para homens e mulheres que desejam se tornar bons esposos e esposas. São autores de alguns livros, entre eles "Casamento Blindado", "120 minutos para blindar seu casamento" e "Bíblia comentada Casamento Blindado" em coautoria e outros assinados individualmente, como "O perfil do jovem de Deus" (de Renato) e "Melhor do que comprar sapatos" e "A Mulher V" (de Cristiane). Além disso, são os apresentadores mais famosos do programa televisivo The Love School, que vai ao ar todos os dias pela Rede Record (o casal apresenta aos sábados), emissora de televisão que Edir Macedo é proprietário.

Neste artigo, propomos uma reflexão sobre a relação publicizada entre relacionamentos afetivos, fé racional ${ }^{2}$ e 'casamento empresa' a partir da análise das narrativas terapêuticas do casal Cardoso e seus desdobramentos na marca The Love School, disponibilizados em diversos espaços (midiáticos ou não) como televisão aberta, internet, livros e no principal templo da IURD ${ }^{3}$. Considerando ainda a amplitude do nosso objeto e a

\footnotetext{
${ }^{1}$ Programa televisivo, livros, revistas, DVDs, cruzeiros etc.

${ }^{2}$ Cujos pilares se encontram numa teologia de resultados, conhecida como 'Teologia da Prosperidade'.

${ }^{3}$ Material coletado durante os meses de abril, maio e junho de 2015 em visitas regulares, às quintas-feiras, no Templo de Salomão em São Paulo, nas reuniões nominadas de Terapia do Amor, estas apresentadas pelo Casal Cardoso.
} 
heterogeneidade do material de análise (principalmente quando nos debruçamos sobre os discursos midiáticos), a nossa opção metodológica priorizou uma perspectiva não restritiva, nem à materialidade linguística, nem aos processos de interação social fora da mídia. O que nos fez reunir, como corpus, diversos textos produzidos pela marca, através de seus representantes, mas igualmente de vários consumidores dela. Alguns desses textos, portanto, conferem a corporificação necessária para os nossos argumentos e estarão inseridos no decorrer deste artigo, nos permitindo uma análise multidimensionada do discurso da The Love School.

Assim sendo, tendo como alicerce estruturante tal abordagem, consideramos pertinente que, antes de nos debruçarmos sobre a análise propriamente dita, ancorada na perspectiva sociodiscursiva, façamos um percurso teórico sobre a noção do eu como projeto reflexivo na modernidade tardia e como isso é perpassado pela cultura empreendedora que racionaliza os afetos e os transforma em objetos mensuráveis.

\section{NARRATIVAS TERAPÊUTICAS E O EU COMO PROJETO REFLEXIVO}

A obra de Illouz (2011) é referência fundamental para a compreensão do projeto reflexivo do eu, em conexão com as questões relativas ao capitalismo afetivo, ao mercado de autoajuda e às narrativas terapêuticas. Neste tópico, retomamos o percurso histórico traçado pela autora para compreensão dos elementos que estão relacionados ao caso de The Love School.

Em contraponto à leitura da racionalidade como fundante no advento da modernidade, Illouz (2011) trata da emergência do homo sentimentalis nesse cenário que, em conexão com o sistema capitalista, vai se consolidar no século XX. Como defende Illouz, "longe de serem pré-sociais ou pré-culturais, os afetos são significados culturais e relações sociais inseparavelmente comprimidos" (2011, p. 9). Nesse sentido, os afetos, inerentes ao ser social, não deveriam ser tangenciados no entendimento sobre como o capitalismo se estrutura e chega aos nossos dias, resultando numa miríade de ofertas de vinculação para os sujeitos, que envolvem institucionalidades, mercados e consumos. A tese central de Illouz é que "a criação do capitalismo caminhou de mãos dadas com a criação de uma cultura afetiva intensamente especializada" (2011, p. 11); o estudo dos fenômenos que se relacionam com essa cultura afetiva oferece "condições de revelar uma outra ordem na organização social do capitalismo" (idem). 
Illouz defende que a linguagem da Psicologia, disciplina originada no final do século XIX e difundida nas primeiras décadas do século XX, teve papel importante na inter-relação entre economia e afetos: "os repertórios de mercado se entrelaçam com a linguagem da psicologia e, combinados, os dois oferecem novas técnicas e sentidos para cunhar novas formas de sociabilidade" (2011, p. 13). A autora menciona o ano de 1909, por conta das conferências realizadas por Sigmund Freud na Universidade Clark, nos Estados Unidos, como um marco na popularização da Psicologia e sua incorporação, entre outras instâncias, na cultura corporativa, por meio de profissionais que levaram técnicas emprestadas dessa disciplina para as políticas de recursos humanos. Essa interinfluência entre economia e afetos só cresceu desde então, e, entre as várias consequências, temos o desenvolvimento do mercado de autoajuda e de outras institucionalidades, que legitimam a leitura do 'eu' em suas patologias modernas e contemporâneas, em sua necessidade contínua de ajustamento e de manutenção da normalidade. Dessa forma,

A psicanálise e a psicologia constituíram minas de ouro para a indústria do aconselhamento, pois eram envoltas pela aura da ciência, podiam ser altamente individualizadas (adequando-se a toda e qualquer particularidade individual), podiam abordar uma ampla variedade de problemas, com isso permitindo a diversificação do produto (ILLOUZ, 2011, p. 19).

The Love School se entrelaça e se identifica com essa indústria do aconselhamento, exatamente nos aspectos de individualização e especialização, ao unir a instituição da família com a doutrina religiosa da Igreja Universal, em combinação com lógicas e preceitos emprestados do mundo corporativo. Nesse sentido, o eu tomado como empresa (cf. FOUCAULT, 2008), como empreendimento a ser autogerenciado, é enquadrado no contexto das relações afetivas e cotidianas do casal. Vejamos, como exemplo, uma das falas de Renato Cardoso:

São os objetivos de uma empresa que guiam tudo o que se faz dentro dela no dia a dia. As decisões que tomam, quem contratam, o treinamento dos funcionários, os produtos que criam, a publicidade que fazem - tudo é movido e guiado pelos objetivos e resultados que a empresa quer alcançar. Quando trazemos esse pensamento para o casamento, verificamos que infelizmente a maioria dos casais não pensa assim. Eles são apanhados pelo corre-corre da vida, se perdem nos sentimentos, e logo perdem de vista os objetivos pelos quais casaram. Quando os objetivos são esquecidos, então as decisões que tomam e tudo mais que fazem dentro da relação já não contribuem para a realização e o sucesso do casamento (CARDOSO; CARDOSO, 2012, p. 61). 
A busca por um relacionamento feliz, bem sucedido, "produtivo", passa a ser a meta ao alcance de todos, ao menos em tese - desde que os preceitos da doutrina/aconselhamento sejam seguidos. A forma prescritiva na qual esses discursos se estruturam é semelhante a um receituário, uma espécie de antídoto contra as patologias e desvios pelos quais os sujeitos são responsabilizados.

É nesse contexto que ganham visibilidade as narrativas terapêuticas tratadas por Illouz (2011), nelas, a trajetória de vida é lida como patologia, como algo a ser transformado para se adequar a modelos biográficos ideais. Estes promovidos, especialmente, pelo mercado de aconselhamento e autoajuda. Nas palavras da autora, ao exemplificar sua tese a partir de um relato, em que o "ser patológico" identifica seu problema na ação "automática", não reflexiva:

a estrutura da narrativa [terapêutica] exige que a pessoa identifique uma patologia - nesse caso, um modo "automático" de ser (entendendo-se o 'automático' como oposto a autodeterminado). Uma vez identificado o comportamento automático, a pessoa estabelece ligações causais com o passado (2011, p. 73-74).

Essa forma narrativa terapêutica, presente em gêneros midiáticos como programas de entrevistas, é bastante significativa em The Love School. As histórias de autorrealização, tanto do casal Cardoso - que serve de modelo ideal, como narrativa canônica para o casamento bem sucedido -, quanto dos seguidores, passam pela exposição do sofrimento, do trauma, das disfunções do passado, que são legitimadoras das conquistas do presente, da harmonia e da boa administração da vida do casal. Nesse sentido, "a narrativa terapêutica transforma os sentimentos (...) em objetos públicos, a serem expostos, discutidos e debatidos. O sujeito participa da esfera pública através da interpretação e da exposição de sentimentos "privados"” (ILLOUZ, 2011, p. 76-77). Essa é, portanto, a base do processo de mercantilização dos afetos, da conversão das "formas afetivas do capital" em "formas monetárias" (p. 96). Estamos, assim, no âmbito do consumo, que é parte fundamental da cadeia produtivo-simbólica de The Love School, com seus diálogos com o mercado concorrencial, e sobre os quais tratamos a seguir.

\section{CASAMENTO BLINDADO, RISCO E CONSUMO ${ }^{4}$}

\footnotetext{
${ }^{4}$ Parte das ideias sobre o "casamento blindado" e sua relação com o consumo, presentes nesse subcapítulo, são baseadas no relato do artigo "Dever e prazer no 'casamento-empresa': transações singulares de controle do amor segundo a Igreja Universal”, de Bárbara Regina Altivo, no contexto do GT Comunicação e Sociabilidade, do Encontro da Compós de 2015, realizado em Brasília, permanecendo inéditas na sua atual formulação para este artigo.
} 
"Fortalecer casamentos, educar casais e solteiros e lutar para que menos casamentos acabem em divórcio se tornou uma missão em minha vida" (CARDOSO; CARDOSO, 2012, p.17). Em um dos trechos mais marcantes do início do livro "Casamento Blindado", escrito em coautoria com sua esposa Cristiane Cardoso, Renato ressalta seu lugar de fala de conselheiro amoroso, especialista em terapia para casais, apresentando seu trabalho em um sentido muito próximo ao de vocação. Como um "chamado", o casal explica repetidamente tanto em publicações como em palestras e cultos - que ajudar homens e mulheres a refazerem seus casamentos se tornou uma missão em suas vidas. Essa descoberta, como sempre lembram, ocorreu a partir do momento que olharam para os próprios problemas e perceberam como era simples solucioná-los. "Falamos a partir de experiências pessoais em nosso casamento e também de anos de aconselhamento de casais" (Idem).

A noção de casamento blindado poderia, perfeitamente, ser circunscrita apenas numa perspectiva secular, no cenário contemporâneo da sociedade de risco, na miragem de que 'as concorrências do mundo' intentam pela dissolução das (sólidas) relações matrimoniais, principalmente se a blindagem referida vem como representação da sociedade individualizada discutida por Beck, na qual as biografias de tornam "autorreflexivas" (2010, p. 199). Contudo, no cerne da marca The Love School, a noção de uma relação matrimonial blindada, parte concomitantemente de uma leitura bíblica dos papéis de homem e mulher, que "devem" ser recuperados para resistir à ideia da degradação moral na vida contemporânea, destruidora, entre outras coisas, da instituição do casamento. Há, portanto, um entrelaçamento claro de dois campos discursivos, à primeira vista distintos e distantes, mas que, diante desse processo de responsabilização dos sujeitos pelo sucesso ou fracasso de suas iniciativas (no qual é preciso "reconhecer-se a si mesmo como foco de ação, como agência de planejamento" (idem)), se aproximam e se mesclam.

Justamente por isso, esse planejamento e gestão de si mesmo não se referem somente à carreira profissional, às capacidades e competências próprias, mas correspondem à ação sobre a vida como um todo, incluindo a gestão familiar e as crenças religiosas (vide a noção de 'fé racional' como proposta pela IURD). Mesmo que os alicerces argumentativos se ancorem nas perspectivas religiosas bíblicas, no casamento - foco do discurso de Renato e Cristiane - a gestão deve seguir modelos empresariais, assim como as performances de cada um na empresa Casamento Ltda. (CARDOSO; CARDOSO, 2010). Como propõe o casal, "há uma maneira eficaz em que homens e mulheres podem resolver os problemas conjugais e evitar 
que se repitam sem ferir ninguém no processo. Eu chamo essa maneira de "tratar seu casamento como uma empresa"'” (Ibid, p.59).

Sendo assim, a blindagem se dará através da introdução de uma série de ações prescritas no livro, como é o caso do "para-raios", ao qual eles dedicam um capítulo inteiro. Em poucas palavras, se trata de "descarregar as emoções" em outro lugar que não seja o cônjuge. "Blindar" o casamento é, por conseguinte, resistir, mesmo que ilusoriamente, aos riscos produzidos pelo mundo atual, especialmente àqueles que atuam mais diretamente no plano do indivíduo, do casal. A racionalidade proposta pelo discurso da The Love School guarda relação direta com a ideia da reflexividade. Como podemos ver corporificado no trecho a seguir:

\begin{abstract}
Nós, homens viciados no trabalho, temos que entender que o casamento também é um tipo de trabalho, uma empresa. Se você não trabalhar no seu casamento, inevitavelmente ele irá à falência. Casamentos felizes dão trabalho e não acontecem por acaso. Quando você vê um casal que está junto por muitos anos e vivendo bem, saiba que aquele casamento não é fruto da sorte. Não é porque 'foram feitos um para o outro' nem porque 'combinam bem'. Se olharmos mais de perto, vamos verificar que aquele casal trabalha constantemente na manutenção do casamento. Depois de 21 anos de casados, Cristiane e eu continuamos trabalhando, agindo em nosso relacionamento. Um descuido, um pouco de preguiça de fazer algo ou um desleixo sobre algo importante já é o suficiente para probleminhas surgirem. Por isso nunca negligenciamos este trabalho (CARDOSO; CARDOSO, 2012, p. 45-46).
\end{abstract}

Nesse espectro da modernidade reflexiva, discutida principalmente por Giddens (2002), à qual Beck está alinhado teoricamente, todos são impelidos à autorreflexão, à autoterapia e à autoajuda. De forma paradoxal, esse "auto" é mediado por sistemas especialistas, como é próprio do mercado da autoajuda e como é o caso da The Love School em seu caráter pedagógico: evocando (principalmente na mídia) a institucionalidade da escola para enunciar um discurso verdadeiramente competente. As sessões de terapia para casais, promovidas no âmbito da Escola e veiculadas na televisão aberta, reforçam a sua vinculação com a cultura terapêutica tratada por autores como Illouz (2011).

Para que ocorram assertividade e aderência discursivas, seja no templo, nas publicações ou nas mídias, o casal sempre reforça o caráter exemplar de suas próprias vidas. Tal manobra discursiva vem atrelada à lembrança que, assim como todos os que assistem ou estão presentes nas reuniões da igreja, eles já tiveram problemas e, com muita fé (racional e/ou inteligente), conseguiram superá-los, tornando-se pessoas autorrealizadas e felizes. Demonstram, na materialidade de seus discursos, o papel fundamental da igreja em suas vidas e o imbricamento dos dois campos que fizemos referência. 
Ainda em relação à tese de Beck, temos a questão da exploração da autobiografia dos líderes da The Love School, como modelos a serem seguidos, como trajetórias de vida institucionalizadas e, principalmente, mercadorizadas. A estratégia que une as "histórias de vida exemplares" (BUONANNO, 2011), como experiência a ser replicada na vida dos fiéis, alunos, seguidores, instaura tais interlocutores como consumidores. Entretanto, em menor grau, esse consumo igualmente vem revestido da aura religiosa. Se, entre as demonizações atribuídas à vida contemporânea, está o consumo lido como consumismo, como desvio dessa 'vida blindada' a dois, as práticas de consumo ofertadas pela Igreja são abençoadas e, para além disso, são imprescindíveis para trilhar o sucesso no casamento. Esse processo faz parte do sistema produtivo da The Love School e da forma como se articulam as interações entre produtores e consumidores, entre o casal ideal e seus seguidores, entre os professores que narrativizam uma leitura própria do amor como modelar e os alunos ansiosos por transportar as "lições de vida" à sua esfera familiar. Como na fala de Renato Cardoso para a divulgação e estímulo à compra-consumo da Bíblia Casamento Blindado, assinada e chancelada pelos apresentadores:

\begin{abstract}
A Bíblia para muita gente é como um labirinto. Quando elas abrem, elas não sabem para onde ir, o que fazer... E pouca gente sabe que a bíblia está cheia de auxílios para a vida amorosa. Solteiros, casados... A bíblia tem sido a base de tudo o que a gente ensina. Então nós pensamos assim: por que não colocar sinais ou placas de trânsito que indicam a direção para que as pessoas, para onde elas devem ir... na Bíblia? Para elas saber onde ler, o que ler, para tirar a mensagem para a vida amorosa. E aí este é o suco do projeto da Bíblia Casamento Blindado [sic] (CANAL THE LOVE SCHOOL, 2015, 00:30).
\end{abstract}

O consumo, nesse caso, é somado à pedagogia ofertada pelos professores da Escola; mas não apenas isso, trata-se de um consumo redentor, diferente - fruto de um investimento de vida e para a vida. Isso se dá porque as narrativas em questão são produzidas dentro de um conjunto específico de crenças que tem a Teologia da Prosperidade como alicerce estrutural, esta que, grosso modo, prega ser legítimo o fiel usufruir de tudo de bom e melhor aqui na Terra, exigindo de Deus o que é seu por direito, pela condição de "filho" (RODRIGUES, 2003). Assim sendo, a "prosperidade", na concepção da Igreja Universal, à qual Renato e Cristiane se afinam ideologicamente, é um direito do crente, desde que este "aja na fé" por meio de sacrifícios financeiros. É por isso que vemos a mesma relação entre dinheiro e resultados aflorar no discurso da marca, principalmente através dos 'investimentos' feitos no 
casamento - com o consumo dos produtos (como a Bíblia Casamento Blindado) e os demais serviços ofertados.

O consumo dos produtos da marca é, dessa forma, estimulado por seus representantes como uma maneira fácil e rápida de resolver problemas e até mesmo de evitá-los, o que é comprovado nos testemunhos dos apresentadores e dos consumidores da The Love School. Fazendo um paralelo com a igreja, assim como o ethos religioso da IURD, o ethos consumista da marca tem como uma das características mais visíveis a externalização da prosperidade via testemunho, demonstrando a concretude do consumo como um meio prático e efetivo para prosperar na vida amorosa e pessoal. Como se pode ver no depoimento de uma consumidora do livro Casamento Blindado:

Entendi que precisava ser mais tolerante. Aprendi a ceder. Aprendi a resolver os meus problemas dentro de casa. Aprendi a sentar com ele e conversar, falar o que sinto sem brigar, sem discutir. Deixo a raiva passar e depois, em outro momento, digo para ele: 'Amor sabe aquele dia? Eu não gostei do que você fez. Não pode melhorar?' Assim as coisas fluem bem melhor. Também assumi meu papel de auxiliadora e compreendi que precisava ajudá-lo para que pudéssemos conquistar nossas coisas. Tanto é que depois que passei a fazer isso, conseguimos comprar a nossa casa e o nosso carro. (...) Esse livro me ajudou muito. Quando acontece alguma coisa, se tenho alguma dúvida, corro para ele. Vou comprar dois para presentear duas amigas que vão casar. Ele não trouxe ensinamentos só para o meu casamento, mas também me fez entender o passado. Parece que foi feito para mim. (Lucinete Correa Alencar, de 36 anos, grifos nossos) ${ }^{5}$

Os abundantes testemunhos da efetividade dos produtos relacionados à marca The Love School revelam indivíduos que se tornam o foco de um sistema produtivo que exige, cada vez mais, ações empreendedoras no que concerne à própria intimidade. Não é difícil, por conseguinte, percebermos o deslocamento da noção de empreendedorismo da esfera econômica para a esfera privada das relações íntimas.

Nesse sentido, os limites entre o público e o privado se borram e o íntimo se torna um produto consumível, na medida em que se apresenta como modelo de conduta. O sucesso está ao alcance de todos e as histórias de superação apresentadas, especialmente na literatura de aconselhamento ou em programas televisivos com propostas semelhantes, são apenas guias e manuais prescritivos para que cada indivíduo possa trilhar o caminho à sua própria maneira. Quando Renato e Cristiane afirmam ser o casamento uma condição necessária para felicidade, constroem um discurso no qual cabe a cada um potencializar-se como objeto desejável ao

5 Trecho retirado do site: http://www.universal.org/noticias/2013/06/18/livro-quotcasamento-blindadoquotpromove-autoconhecimento-23652.html. Acesso em 18 jul. 2015. 
outro: “A pessoa, seja uma mulher ou seja um homem, que quer um dia se casar, tem que começar agora, mesmo sem namorado, sem ninguém, começar a se preparar para ser um homem ou uma mulher casada" (CANAL THE LOVE SCHOOL, 2015, 20:34). A felicidade, dessa forma, vincula-se ao casamento bem-sucedido - logo, às formas racionais de conduta.

\section{O AMOR INTELIGENTE: A RACIONALIZAÇÃO DOS AFETOS NA ESCOLA DO AMOR}

Antes de tratarmos da racionalização dos afetos na The Love School - para a emergência de um amor dito 'inteligente' -, consideramos pertinente certa digressão conceitual, visto que a ancoragem discursiva da Escola do Amor encontra guarida no 'racionalismo do protestantismo', como postulado por Weber $(1963$, p.248) ao assinalar que este impunha o "domínio racional do mundo".

Com efeito, o autor, na sua explicação acerca do modelo ocidental de racionalização, elenca alguns processos sociais e culturais considerados fundamentais e amplamente abrangentes. Estes versam desde o "desencanto e a intelectualização do mundo", estruturados na tendência de observação do mundo como resultado de uma construção causal: sujeita, portanto, ao controle racional; até "a crescente importância do conhecimento técnico especializado em economia, administração e educação", entre outros - todos favorecendo mais a racionalidade formal do que a substantiva e estimulando a calculabilidade da ação (BRUKAKER, 1996, p.642). Consequentemente, contemplamos o modus operandi da IURD como parte do próprio processo constituinte do modelo ocidental da racionalização, justificado, principalmente, por sua particularidade 'protestante', de domínio racional do mundo.

Por outro lado, a proposição de uma fé inteligente, capaz de gerar a racionalidade dos afetos, parece contraditória na sua própria perspectiva fundante, essencialmente religiosa. Afinal, estamos lidando com líderes religiosos que ancoram seus discursos na Bíblia ${ }^{6}$ e esta define a fé, como "a certeza de coisas que se esperam, a convicção de fatos que se não veem" (BÍBLIA, Hebreus, 11:1) e que a fé "é dom de Deus" (BÍBLIA, Efésios, 2:8), logo, com certo

\footnotetext{
${ }^{6}$ Nós não queremos que as pessoas fiquem dependentes da Escola do Amor, né? Porque a bíblia é uma fonte. A Escola do Amor tem pego da fonte, que é a bíblia. Muitas, muitas dicas, muitos ensinamentos, muitos conselhos vêm da palavra de Deus. Se as pessoas souberem ler a palavra de Deus, se elas souberem meditar na palavra de Deus, elas não vão depender de ninguém nesse mundo (Cristiane, CANAL THE LOVE SCHOOL, 2010).
} 
distanciamento da mera construção causal, visto que, sendo "dada por Deus", como 'dádiva' não está sujeita ao controle racional.

Não obstante essa circunscrição bíblica para a definição do que é fé, o conceito de 'fé inteligente', quando posto em diálogo com as dimensões emocionais e religiosas, é largamente difundido no seio da Igreja Universal, lócus onde Renato e Cristiane desenvolvem as noções de 'amor inteligente' e de 'casamento empresa', como formas racionais de lidar com questões referentes ao relacionamento a dois:

O segredo das empresas de sucesso é não usar a emoção para resolver problemas, e sim a razão. Entendem que não se resolve nada usando sentimentos. Local de trabalho é lugar de inteligência e atitude, não de sentimentalismo, nem de sentir isso ou aquilo, Por isso, alcançam seus objetivos independentemente dos sentimentos dos funcionários, e mesmo a despeito de um funcionário não gostar muito do outro. Nessas empresas, se aprende a separar o trabalho das pessoas, e não misturar as duas coisas. (...) Emoção é ferramenta errada para resolver problemas no trabalho e também no casamento. (...) Usando a razão e não a emoção para resolver problemas, as empresas mantêm dezenas, centenas, até milhares de funcionários unidos em um só objetivo - mesmo sem se amarem. Com certeza, um casal que se ama inteligentemente também pode se beneficiar dessa mesma ferramenta para se manter juntos e resolver seus problemas (CARDOSO; CARDOSO, 2012, pp. 63; 66).

Como demarcam constantemente, agir racionalmente em um relacionamento amoroso significa construir uma metodologia própria, mas que guarda grande similaridade com os procedimentos observados nas gestões empresariais para lidar com os conflitos provenientes das diferenças entre as pessoas (inclusive, descritos nas publicações da marca, de forma comparativa). O caráter utilitário presente em ambas as ideias se efetiva na fala do casal, quando igualmente afirmam que "a fé não é uma coisa religiosa, e sim algo extremamente inteligente. Quando aprende a usar sua fé com inteligência, você consegue tirar proveito da fé para resolver problemas do cotidiano" (CARDOSO; CARDOSO, 2010, p.89).

É justamente nessa chave que a fé racional é construída. Silenciando alguns dos postulados bíblicos e promovendo interpretações que devem favorecer o surgimento das premissas que ancoraram as atitudes ensinadas sobre o 'amor inteligente' e sobre o 'casamento empresa'. Tais ideias, como propagadas pelo casal Cardoso, são totalmente pautadas na racionalização dos afetos e na reduzida importância dada a 'fé religiosa', como o modo de maximizar os efeitos benéficos de uma relação, tal como o aumento no índice de felicidade pessoal e profissional.

Nosso método é mais eficaz: ajudá-lo a enxergar o verdadeiro problema, encontrar a raiz, eliminá-lo e evitar que volte. Uma das coisas que nos 
intrigou foi descobrir que o índice de divórcios não varia muito entre pessoas de orientação cristã e pessoas não religiosas. A crença em Deus, o autor do casamento, parece não ser suficiente para evitar que uma pessoa se divorcie. Isso é no mínimo curioso, pois se há um grupo que deveria ser mais hábil em manter o casamento, esse grupo é o das pessoas que creem em Deus. Mas por que isso não acontece? (CARDOSO; CARDOSO, 2012, p.49)

O mesmo se prega nas reuniões ministradas por Renato no Templo de Salomão, em São Paulo, a Terapia do Amor, culto ao qual a marca está vinculada. Em uma de suas recorrentes falas, ter fé não é suficiente, é preciso agir de maneira racional, praticá-la inteligentemente para alcançar seus propósitos. Nesse sentido, a reunião tem como proposta oferecer, principalmente, dois tipos de ajuda aos participantes: a primeira é a palavra, ou seja, a orientação. A segunda é ensinar a exercer uma fé inteligente, racional, utilizando-a como ferramenta para alcançar o sucesso em tudo o que se deseja. Mas lembram: "As dicas nem sempre resolvem os problemas, pois é a fé [nesse caso, racional] que move montanhas", responsabilizando o indivíduo pela condução de sua vida e atribuindo-lhe a 'culpa' pelo 'não alcance' dos seus objetivos.

\section{CONSIDERAÇÕES FINAIS}

Não são novidades que o campo religioso sempre atuou na construção de discursos norteadores sobre a gestão de si e dos afetos e que, algumas igrejas, principalmente as agrupadas nas vertentes ligadas à Teologia da Prosperidade, tenham seus modelos de conduta prescritos em 'manuais de autoajuda' diversos, como alguns dos produtos da The Love School.

Consequentemente, em uma sociedade marcada pela racionalização em todos os âmbitos da vida ('domínio racional do mundo', conforme Weber, 1963), não é estranho considerar que os agentes religiosos da contemporaneidade organizam suas ações com base nas premissas do mercado. Em paralelo, vislumbramos demandas de ordem existencial do eu, que agora passa a ser "visto como um projeto reflexivo, pelo qual o indivíduo é responsável [...]. Somos não o que somos, mas o que fazemos de nós mesmos" (GIDDENS, 2002, p.74).

Questões existenciais, assim como as da ordem dos afetos, são incorporadas pelo sistema capitalista e traduzidas em uma linguagem de mercado, transformando a vida e os sentimentos íntimos em objetos mensuráveis (ILLOUZ, 2011). Desse processo de racionalização do mundo e das práticas sociais, observamos a expansão de sistemas 
especialistas que prometem respostas a tais questionamentos e a prescrição de maneiras de "ser feliz" e "autorrealizado".

Com efeito, em uma dicotômica relação entre o que é normal e o que é patológico, a autorrealização hoje é apresentada em um vasto conjunto de discursos, como o sentido próprio da trajetória do eu. Tal condição, porém, como disponibilizada nos manuais de autoajuda, exige alta performance do indivíduo, de modo que conceba a vida como um empreendimento autogerido. Os afetos são então racionalizados, apropriados pelo sistema capitalista e enquadrados em narrativas que apresentam fórmulas para se alcançar a felicidade.

Nessa conjuntura, ao construir uma narrativa de si sobre a gestão do eu e dos afetos, Renato e Cristiane promovem uma concepção racionalizada da vida, na qual o indivíduo deve fazer-se a si próprio como alguém autorrealizado, seguindo os modelos de felicidade por eles propostos. Com um discurso terapêutico pautado em premissas religiosas (mesmo que algumas modalizadas), o casal Cardoso narrativiza sua história e comercializa sua biografia com uma referência muito próxima à literatura de aconselhamento (autoajuda) e de gestão empresarial.

Todavia, o diferencial desse discurso está no modo como se processa a relação entre religião, empreendedorismo e afeto nas narrativas terapêuticas autobiográficas, promovendo um ideal de felicidade alicerçado em uma teologia de resultados. Esta que guarda uma íntima e profícua afinidade com o tema da prosperidade, "presente tanto no constructo teórico que fundamenta o mercado na sociedade capitalista, quanto no discurso pastoral da IURD" (RODRIGUES, 2003, p.81). Para tanto, assim como o fiel, o consumidor da marca deve determinar (através da verbalização) que sua vida (incluindo as relações matrimoniais e afetivas) será transformada. Em outras palavras, é imprescindível agir na fé (racional e inteligente), investindo em si próprio e no seu desempenho.

Nesse sentido, nos parece razoável concluir que as narrativas em pauta se constituem como modelos de ação no âmbito das relações afetivas dentro da própria Igreja Universal, mas não apenas isto, visto que, ao estudá-las, vemos desdobramentos constituintes para a formação identitária de uma marca que, mesmo nascida nos domínios eclesiásticos, parece se distanciar discursivamente de seus parâmetros religiosos fundantes, principalmente quando reduz a importância destes, em detrimento da inteligência, da razão e, principalmente, do mercado. 


\section{REFERÊNCIAS}

ALMEIDA, João Ferreira de. Trad. A Bíblia Sagrada (revista e atualizada no Brasil) 2 ed. São Paulo. Sociedade Bíblica Brasileira, 1993.

BECK, U. Sociedade de risco: rumo a uma outra modernidade. São Paulo: Ed. 34, 2010.

BRUBAKER, William. Racionalização. In: Dicionário do Pensamento Social do Século XX. / Ed. por William Outhwaite, Tom Bottomore. Trad. Eduardo Francisco Alves, Álvaro Cabral.Rio de Janeiro: Jorge Zahar Ed., 1996.

BUONANNO, M. Histórias de vida exemplares. Biografias. MATRIZes, ECA/USP, ano 5, no.1, p.63-84, jul/dez 2011.

CANAL THE LOVE SCHOOL. Como foi o lançamento da Bíblia Casamento Blindado.

Disponível em: < https://www.youtube.com/watch?v=i9XU87h6f4k> Acesso em abr. 2015.

. Especial: Casamento Blindado. Disponível em:

<https://www.youtube.com/watch?v=zwV26z6J8OY> Acesso em fev. 2015.

Mito da solteirice. Disponível em: <https://www.youtube.com/watch?v=pKx19f83ck0>

Acesso em fev. 2015.

Todo mundo quer casar. Disponível em: <

https://www.youtube.com/watch?v=LBKDDeV6p8Q\&list=PLQ5Pn_wB-

6D09brTGaL1HIN5kqhtbsF3t\&index=2> Acesso em jul. 2015.

CARDOSO, Renato; CARDOSO, Cristiane. Casamento blindado: o seu casamento à prova de divórcio. Rio de Janeiro: Thomas Nelson Brasil, 2012.

EHRENBERG, Alain. O culto da performance: da aventura empreendedora à depressão nervosa. São Paulo: Ideias \& Letras, 2010.

FOUCAULT, M. Nascimento da biopolítica: curso dado no Collège de France (1978-1979). São Paulo: Martins Fontes, 2008.

GIDDENS, A. Modernidade e identidade. Rio de Janeiro: Zahar, 2002.

ILLOUZ, E. O amor nos tempos do capitalismo. Rio de Janeiro: Zahar, 2011.

MACEDO, Edir. Fé Racional. Rio de Janeiro: Unipro, 2010.

RODRIGUES, Kleber Fernando. Teologia da Prosperidade, sagrado e mercado: um estudo sobre a Igreja Universal do Reino de Deus em Caruaru-PE. São Paulo: Edições ABHR: Edições FAFICA, 2003.

WEBER, Max. Ensaios de sociologia. Organização e introdução de H. G. Gerth e C. Wright Mills. Rio de Janeiro, Zahar Editores, 1963. 
Original recebido em: 03 de julho de 2016

Aceito para publicação em: 30 de março de 2017

Karla Regina Macena Pereira Patriota

Professora associada do Programa de Pós-graduação em Comunicação da Universidade Federal de Pernambuco - PPGCOM - UFPE. Doutora em Sociologia e Mestre em Comunicação pela Universidade Federal de Pernambuco, com pós-doutorado em Antropologia Social, pela Universidade de Cambridge - UK

Vander Casaqui

Professor do Programa de Pós-Graduação em Comunicação e Práticas de Consumo da Escola Superior de Propaganda e Marketing - PPGCOM ESPM. Doutor em Ciências da Comunicação pela Universidade de São Paulo (USP), com pós-doutorado pela Universidade Nova de Lisboa.

Emanuelle Rodrigues

Professora do curso de Comunicação da Universidade Federal de Alagoas - UFAL. Mestre em Comunicação pela Universidade Federal de Pernambuco - UFPE.

Esta obra está licenciada sob uma Licença Creative Commons. 